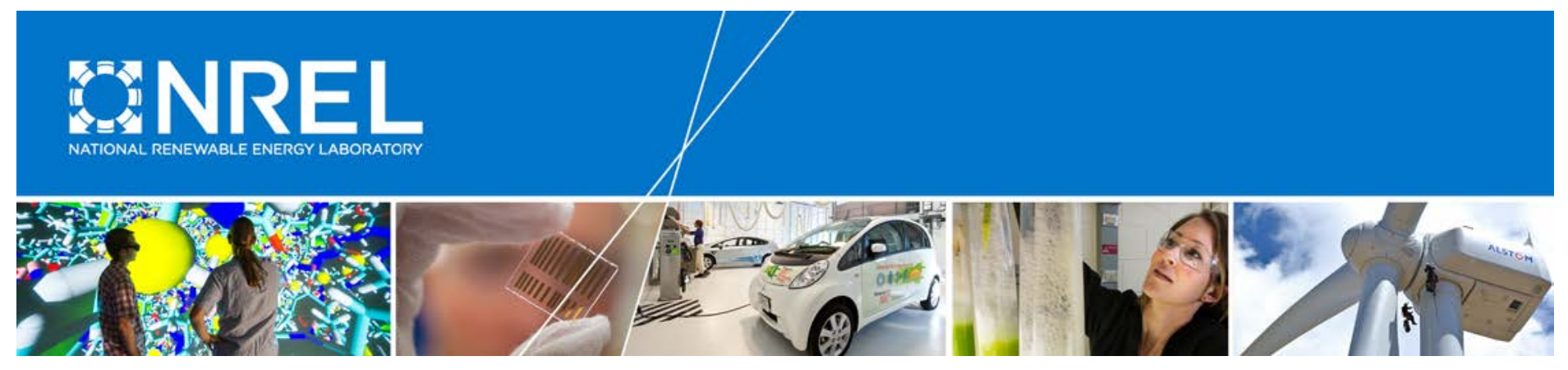

\title{
Residential Indoor Temperature Study
}

Chuck Booten, Joseph Robertson, and Dane Christensen

National Renewable Energy Laboratory

Mike Heaney

Arrow Electronics

David Brown

University of Virginia

Paul Norton

Norton Energy Research and Development

Chris Smith

Ingersoll-Rand Corporation

NREL is a national laboratory of the U.S. Department of Energy Office of Energy Efficiency \& Renewable Energy

Operated by the Alliance for Sustainable Energy, LLC

This report is available at no cost from the National Renewable Energy Laboratory (NREL) at www.nrel.gov/publications.

Technical Report

NREL/TP-5500-68019

April 2017

Contract No. DE-AC36-08G028308 


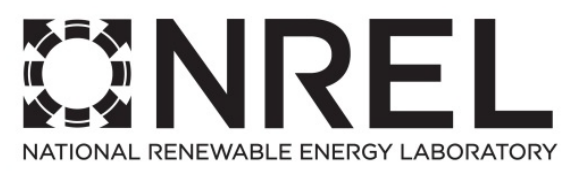

\section{Residential Indoor Temperature Study}

Chuck Booten, Joseph Robertson, and Dane Christensen

National Renewable Energy Laboratory

Mike Heaney

Arrow Electronics

David Brown

University of Virginia

Paul Norton

Norton Energy Research and Development

Chris Smith

Ingersoll-Rand Corporation

Prepared under Task No. BE4R0207

NREL is a national laboratory of the U.S. Department of Energy Office of Energy Efficiency \& Renewable Energy Operated by the Alliance for Sustainable Energy, LLC

This report is available at no cost from the National Renewable Energy Laboratory (NREL) at www.nrel.gov/publications.

National Renewable Energy Laboratory 15013 Denver West Parkway Golden, CO 80401

303-275-3000 • www.nrel.gov
Technical Report

NREL/TP-5500-68019

April 2017

Contract No. DE-AC36-08G028308 


\section{NOTICE}

This report was prepared as an account of work sponsored by an agency of the United States government. Neither the United States government nor any agency thereof, nor any of their employees, makes any warranty, express or implied, or assumes any legal liability or responsibility for the accuracy, completeness, or usefulness of any information, apparatus, product, or process disclosed, or represents that its use would not infringe privately owned rights. Reference herein to any specific commercial product, process, or service by trade name, trademark, manufacturer, or otherwise does not necessarily constitute or imply its endorsement, recommendation, or favoring by the United States government or any agency thereof. The views and opinions of authors expressed herein do not necessarily state or reflect those of the United States government or any agency thereof.

This report is available at no cost from the National Renewable Energy Laboratory (NREL) at www.nrel.gov/publications.

Available electronically at SciTech Connect http:/www.osti.gov/scitech

Available for a processing fee to U.S. Department of Energy and its contractors, in paper, from:

U.S. Department of Energy

Office of Scientific and Technical Information

P.O. Box 62

Oak Ridge, TN 37831-0062

OSTI http://www.osti.gov

Phone: 865.576.8401

Fax: 865.576.5728

Email: reports@osti.gov

Available for sale to the public, in paper, from:

U.S. Department of Commerce

National Technical Information Service

5301 Shawnee Road

Alexandria, VA 22312

NTIS http://www.ntis.gov

Phone: 800.553 .6847 or 703.605 .6000

Fax: 703.605.6900

Email: orders@ntis.gov 


\section{Acknowledgments}

The authors would like to thank the U.S. Department of Energy Building Technologies Office and the Building America Program for financial support. In addition, the authors thank Ed Hancock of Mountain Energy Partnership for his assistance in data collection, as well as Andrew Poerschke from IBACOS and Eric Martin from the Florida Solar Energy Center for their help providing and analyzing data. A final thank you goes to Mike Heaney, formerly of the National Renewable Energy Laboratory, for his contributions to this study. 


\section{List of Acronyms}

BA

BEopt $^{\mathrm{TM}}$

DOE

HSP

HVAC

IECC

NREL

RITS

\section{Building America}

Building Energy Optimization software

U.S. Department of Energy

House Simulation Protocol

Heating, Ventilating, and Air Conditioning

International Energy Conservation Code

National Renewable Energy Laboratory

Residential Indoor Temperature Study 


\section{Executive Summary}

The indoor temperature of homes is broadly used for many business purposes including building design, efficiency incentives, and equipment specification. Homes are simulated to assess energy costs and savings potential, risk of moisture build-up, and cost-effectiveness of improvements in construction and energy codes. Many utilities base energy efficiency incentives, at least in part, on assumptions of thermostat set points. Air conditioner manufacturers, distributors, and installation technicians design, manufacture, and select equipment for new homes, as well as equipment replacements in existing homes based on load calculations that critically rely on indoor temperature. When assessing the energy performance of heating, ventilating, and air conditioning (HVAC) systems; building insulation; and other devices such as heat pump water heaters, the heating and cooling set points are typically the most influential factors driving energy consumption (Robertson et al. 2013). In addition, the indoor temperature in any part of a house is not guaranteed to match the thermostat set point - data show temperatures can vary widely from floor to floor, room to room (Roberts and Lay 2013).

Despite their importance in our understanding of how homes use energy, and for assessing opportunities to reduce home energy consumption, home set points are generally not well-studied; notable exceptions are Roberts and Lay 2013, as well as Parker 2013. Anecdotally, there is a large variance in nearly all occupant-driven aspects of residential energy use (Seryak and Kissock 2003). Most comfort research historically focused on commercial buildings, where many people work in a common environment and effort is made to minimize any dissatisfaction across a population (Fanger 1970, Fanger 2001, ASHRAE 55). In any home, the population is comparatively smaller and occupants have direct control over the HVAC set points. Privacy is another key barrier to collecting information about occupant-driven aspects of home operation. The emergence of new technology - connected thermostats - presents an opportunity for new insights by evaluating large datasets of set points and actual indoor temperatures across climate regions, housing types, etcetera, while avoiding some of the prior barriers.

This study expands on the body of knowledge around answering the question: What are good assumptions for HVAC set points in U.S. homes? Indoor temperature data from U.S. homes were collected and analyzed using funding from the U.S. Department of Energy's Building

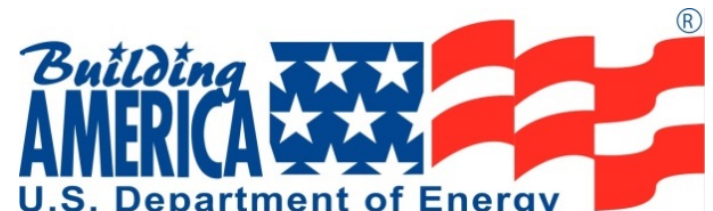

U.S. Department of Energy America (BA) Program, due to the program's reliance on accurate energy simulation of homes. Simulations are used to set BA goals, predict the impact of new building techniques and technologies, inform research objectives, evaluate home performance, optimize efficiency packages to meet savings goals, customize savings approaches to specific climate zones, and myriad other uses. The BA House Simulation Protocols (HSPs) were established to standardize simulation input values (Wilson et al. 2014), and they have been adopted by a number of other local and national programs as well. It is therefore critical to ensure HSPs reflect, as accurately as possible, how U.S. homeowners actually manage comfort settings in their homes.

Detailed data were collected from 327 homes in five different BA climate zones. These data were used to guide analysis of a much larger dataset from Trane ${ }^{\circledR}$ web-connected thermostats by identifying correlations between home characteristics and temperature set points. The mean indoor temperature observed from the web-connected thermostats during the heating season was $70 \pm$ $0.1^{\circ} \mathrm{F}$. The mean indoor temperature observed during the cooling season was $74.9 \pm 0.1^{\circ} \mathrm{F}$. 
However, the data clearly demonstrate that indoor temperatures were highly variable between homes and strongly related to climate.

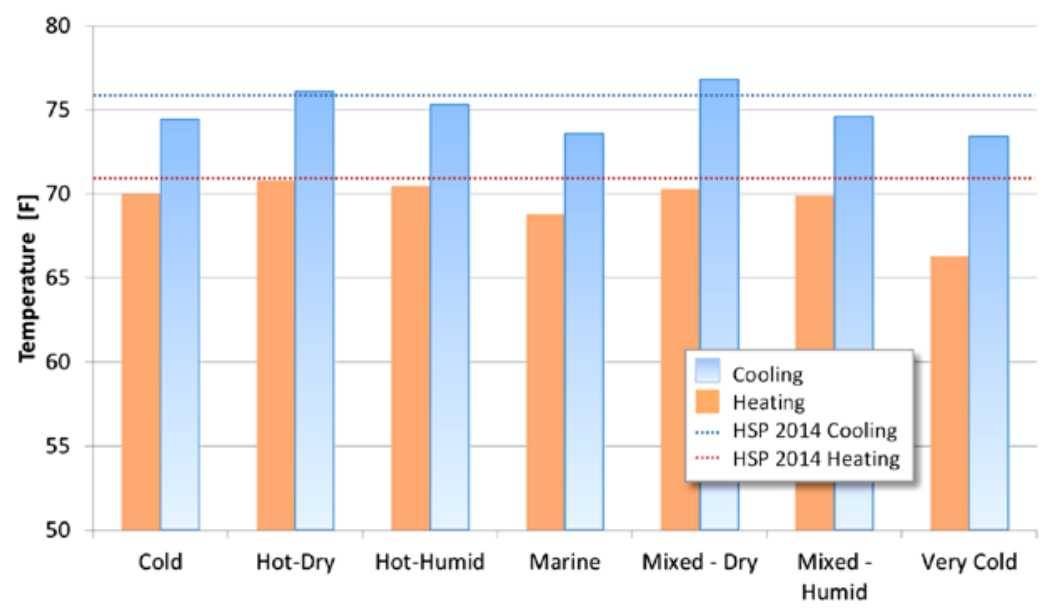

Figure E1. Variable indoor temperatures in homes strongly relate to climate zone

The high level of indoor temperature variability across homes during heating or cooling suggests that improving standard simulation protocols, such as implementing climate-dependent indoor set point assumptions, could lead to more accurate building simulations. 


\section{Table of Contents}

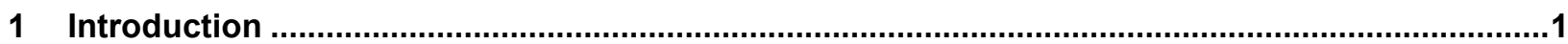

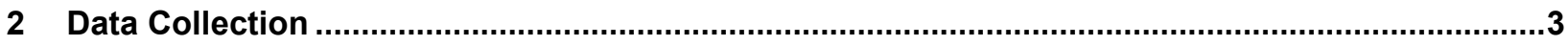

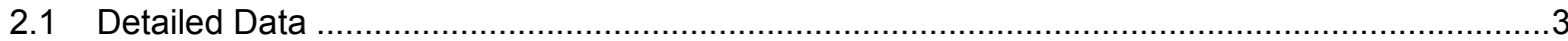

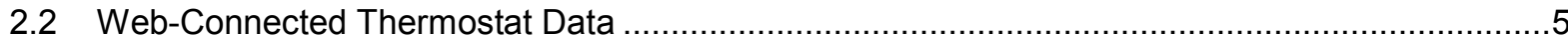

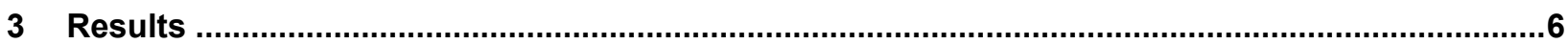

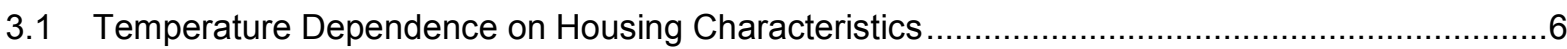

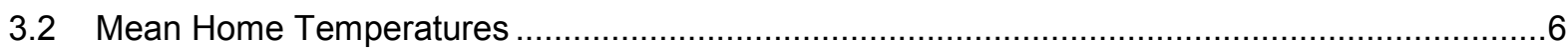

3.2.1 Determination of Heating and Cooling Periods .............................................................

3.2.2 Heating and Cooling Temperature Averages .........................................................

3.2.3 Heating Results by Climate and Equipment Type ..................................................

3.2.4 Cooling Results by Climate and Equipment Type .................................................10

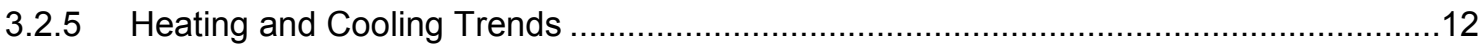

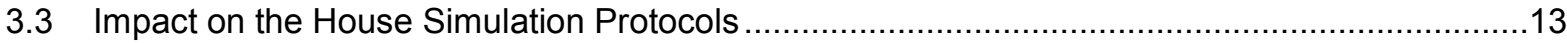

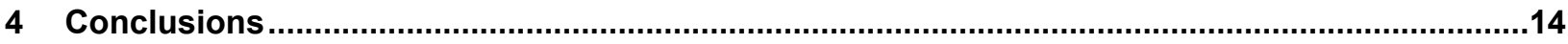

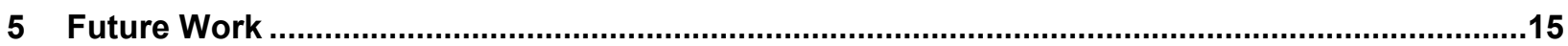

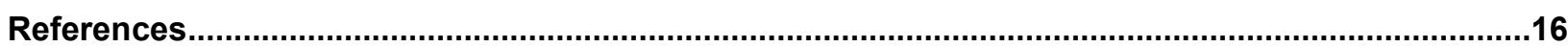




\section{List of Figures}

Figure E1. Variable indoor temperatures in homes strongly relate to climate zone vi

Figure 1. Locations of detailed data homes; marker size is approximately proportional to the number of

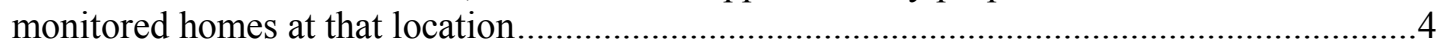

Figure 2. Mean annual indoor temperatures from detailed home data ................................................. 8

Figure 3. Mean annual indoor temperatures from web-connected thermostats .........................................9

Figure 4. Mean annual indoor temperatures during heating and cooling for each climate ........................12

\section{List of Tables}

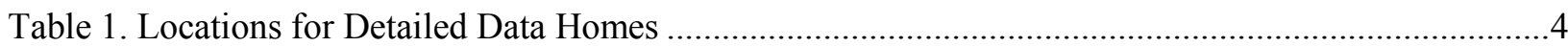

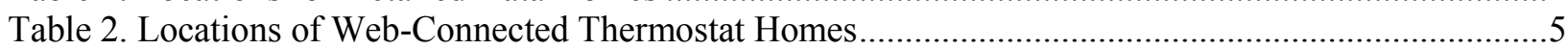

Table 3. Housing Characteristics' Correlation to Measured Temperatures..................................................6

Table 4. Mean Heating and Cooling Values....................................................................................

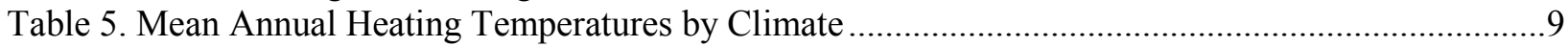

Table 6. Mean Annual Heating Temperatures by Equipment Type .........................................................10

Table 7. Mean Annual Heating Temperatures by Equipment Type and Climate.......................................10

Table 8. Mean Annual Cooling Temperatures by Climate .........................................................................11

Table 9. Mean Annual Cooling Temperatures by Cooling Equipment Type ..........................................11

Table 10. Mean Annual Cooling Temperatures by Equipment Type and Climate ..................................12

Table 11. BEopt Energy Impact of Using Web-Connected Thermostat Temperature Findings Compared to

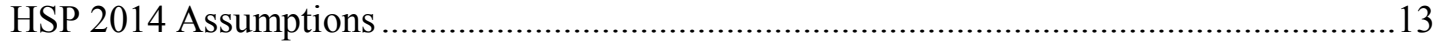




\section{Introduction}

The indoor temperature of homes is used for many purposes including building design, efficiency incentives, and equipment specification. Homes are simulated to assess energy costs and savings potential, risk of moisture build-up, and impacts of energy code improvements. Many utilities base energy efficiency incentives, at least in part, on assumptions of thermostat set points. Air conditioner manufacturers, distributors, and installation technicians design, manufacture, and select equipment for new homes, as well as equipment replacements in existing homes based on load calculations that critically rely on indoor temperature. When assessing the energy performance of heating, ventilating, and air conditioning (HVAC) systems; building insulation; and other devices such as heat pump water heaters, the heating and cooling set points are typically the most influential factors driving energy consumption (Robertson et al. 2013). As stated by Robertson, et al., the assumed heating and cooling set points are generally the most influential simulation inputs; even a $1^{\circ} \mathrm{F}$ difference in a heating set point can make a $5 \%$ difference in heating energy use. Finally, the indoor temperature in any part of a house is not guaranteed to match the thermostat set point - data show temperatures can vary widely from floor to floor, room to room (Roberts and Lay 2013).

Despite their importance in our understanding of how homes use energy, and for assessing opportunities to reduce home energy consumption, home set points are not well-studied. Anecdotally, there is a large variance in nearly all occupant-driven aspects of residential energy use (Seryak and Kissock 2003). Most comfort research historically focused on commercial buildings, where many people work in a common environment and effort is made to minimize dissatisfaction across a population (Fanger 1970, Fanger 2001, ASHRAE 55). In any home, the population is comparatively smaller and occupants have direct control over the HVAC set points. Privacy is another key barrier to collecting information about occupant-driven aspects of home operation. The emergence of new technology_connected thermostats - presents an opportunity for new insights by evaluating large datasets such as set points and actual indoor temperatures across climate regions, housing types, etcetera, while avoiding some of the prior barriers.

This Residential Indoor Temperature Study (RITS) adds to the body of knowledge around answering the question: What are good assumptions for HVAC set points in U.S. homes? Indoor temperature data from U.S. homes were collected and analyzed using funding from the U.S. Department of Energy's Building America (BA) Program. Simulations are used to set BA goals, predict the impact of new building techniques and technologies, inform research objectives, evaluate home performance, optimize efficiency packages to meet savings goals, customize savings approaches to specific climate zones, and myriad other uses. The BA House Simulation Protocols (HSPs) establish standardized simulation input values (Wilson et al. 2014), and have been adopted by a number of other local and national programs as well. It is therefore critical to ensure HSPs reflect, as accurately as possible, how U.S. homeowners actually manage comfort settings in their homes.

Studies like the RITS have been performed in Europe (Johansson et al. 2013, Bagge and Johansson 2013); however, similar work in the United States has been limited (Roberts and Lay 2013, Parker 2013). The National Renewable Energy Laboratory (NREL) partnered with Trane to include data from their web-connected thermostats to increase the sample to several thousand homes. RITS provides significant valuable insights into thermal characteristics of houses and 
occupant behavior related to thermostat usage that have not previously been provided by the private sector or in previously published research.

The homes in this study were, on average, operated approximately $1.0^{\circ} \mathrm{F}$ cooler than current standard residential set point assumptions in the HSPs. There were also regional differences in set point behavior across the population studied. Maintaining the current practice of a set point assumption independent of climate may result in error in the prediction of energy performance up to $8-10 \%$, and skew expectations for investment paybacks and energy costs. Details of regional and equipment-dependent thermostat trends are provided in this report.

Establishing simulation protocols such as thermostat set point assumptions, while critical to assure modeling accuracy and consistency, is generally beyond the scope of private sector research. The U.S. Department of Energy (DOE) is in a unique position to make simulation protocols for use by its programs available for adoption by other interested parties; the Residential Energy Services Network and Building Performance Institute have both adopted portions of the HSPs. The national scope and broad impact of the RITS benefits private and public research, development, and energy efficient technology deployment nationwide. 


\section{Data Collection}

This study aggregates data from multiple sources. The most detailed data, including house characteristics along with measured indoor temperatures, were collected in collaboration with the BA teams concurrent with other research studies, each with its own independent research objective separate from this work. The detailed data have the advantage of including home characteristics that could influence indoor temperatures; however, due to the cost of collecting highly detailed data, the sample size is limited. Data from web-connected thermostats augment the detailed data, providing a large sampling size. To effectively use these two disparate datasets, the detailed data are used to determine home and HVAC system characteristics, while the webconnected thermostat data are used to determine mean temperatures.

The web-connected thermostat data include temperatures measured at the thermostat itself, as well as from any remote sensors that control different zones within the home. Detailed home data are similar, though actual thermostat readings are not recorded; rather, a temperature sensor was placed next to the thermostat. If multiple temperatures are present from a given home, they are averaged to provide a single indoor temperature.

For the purposes of this study, measured temperatures equivalent to simulation model set point inputs are considered. In reality, this is not always true. Temperature variations occur throughout every house, and thermostats have a deadband within which the actual temperature at the thermostat fluctuates. DOE's primary building simulation engine, EnergyPlus (DOE 2013), assumes that the actual temperature of a building or zone is kept at precisely the set point temperature, neglecting all real-word variation within the deadband as long as the equipment has the necessary capacity. Under this paradigm, the measured indoor temperature value is a sufficient approximation to use as a simulation thermostat set point input.

\subsection{Detailed Data}

Detailed data were obtained from test sites coordinated by BA teams: the Florida Solar Energy Center, IBACOS, Steven Winters Associates, and the Levy Partnership and Building Science Corporation. Additional data were obtained from the Northwest Energy Efficiency Alliance residential building stock assessment (Storm et al. 2013). There are complete, detailed datasets from 327 homes as shown in Table 1 and Figure 1. All include measured temperature data from multiple rooms in the house, sampled hourly. The data include both single-family and multifamily homes across several climate zones and were typically collected with temporary data loggers such as $\mathrm{HOBO}^{\circledR}$ or with T-type thermocouples read by a Campbell Scientific ${ }^{\circledR}$ data acquisition system. Data density ranged from one to seven indoor temperature measurements within each home, plus outdoor temperature. Asset characteristics such as climate region, age, size, and HVAC system type were also collected for each home. Not every house included all relevant information; however, the data are generally quite detailed. These data were used to correlate building and HVAC system characteristics with set point temperatures. 
Table 1. Locations for Detailed Data Homes

\begin{tabular}{l|ccccc}
\hline Location & $\begin{array}{c}\text { Number } \\
\text { of Homes }\end{array}$ & $\begin{array}{c}\text { Months of } \\
\text { Data }\end{array}$ & $\begin{array}{c}\text { Type of } \\
\text { Homes }\end{array}$ & $\begin{array}{c}\text { BA Climate } \\
\text { Zone }\end{array}$ & $\begin{array}{c}\text { IECC } \\
\text { Climate } \\
\text { Zone }\end{array}$ \\
\hline California & 6 & 12 & Single-Family & Hot-Dry & $3 \mathrm{~B}$ \\
\hline Colorado & 9 & 2 & Apartment & Cold & $6 \mathrm{~B}$ \\
\hline Colorado & 7 & 12 & Single-Family & Cold & $5 \mathrm{~B}$ \\
\hline Florida & 94 & 12 & Single-Family & Hot-Humid & $2 \mathrm{~A}$ \\
\hline Idaho & 14 & 24 & Single-Family & Cold & $5 \mathrm{~B}$ \\
\hline Louisiana & 10 & 17 & Single-Family & Hot-Humid & $2 \mathrm{~A}$ \\
\hline Maryland & 28 & 23 & Townhome & Mixed-Humid & $4 \mathrm{~A}$ \\
\hline Massachusetts & 11 & 9 & Apartment & Cold & $5 \mathrm{~A}$ \\
\hline Massachusetts & 8 & 13 & Single-Family & Cold & $5 \mathrm{~A}$ \\
\hline New York & 20 & 12 & Single-Family & Cold & 5A/6A \\
\hline Oregon & 40 & 12 & Single-Family & Marine & $4 \mathrm{C}$ \\
\hline Texas & 18 & 12 & Single-Family & Hot-Humid & $2 \mathrm{~A}$ \\
\hline Washington & 16 & 24 & Single-Family & Cold & 5B \\
\hline Washington & 46 & 12 & Single-Family & Marine & $4 \mathrm{C}$ \\
\hline Total & 327 & & & & \\
\hline
\end{tabular}

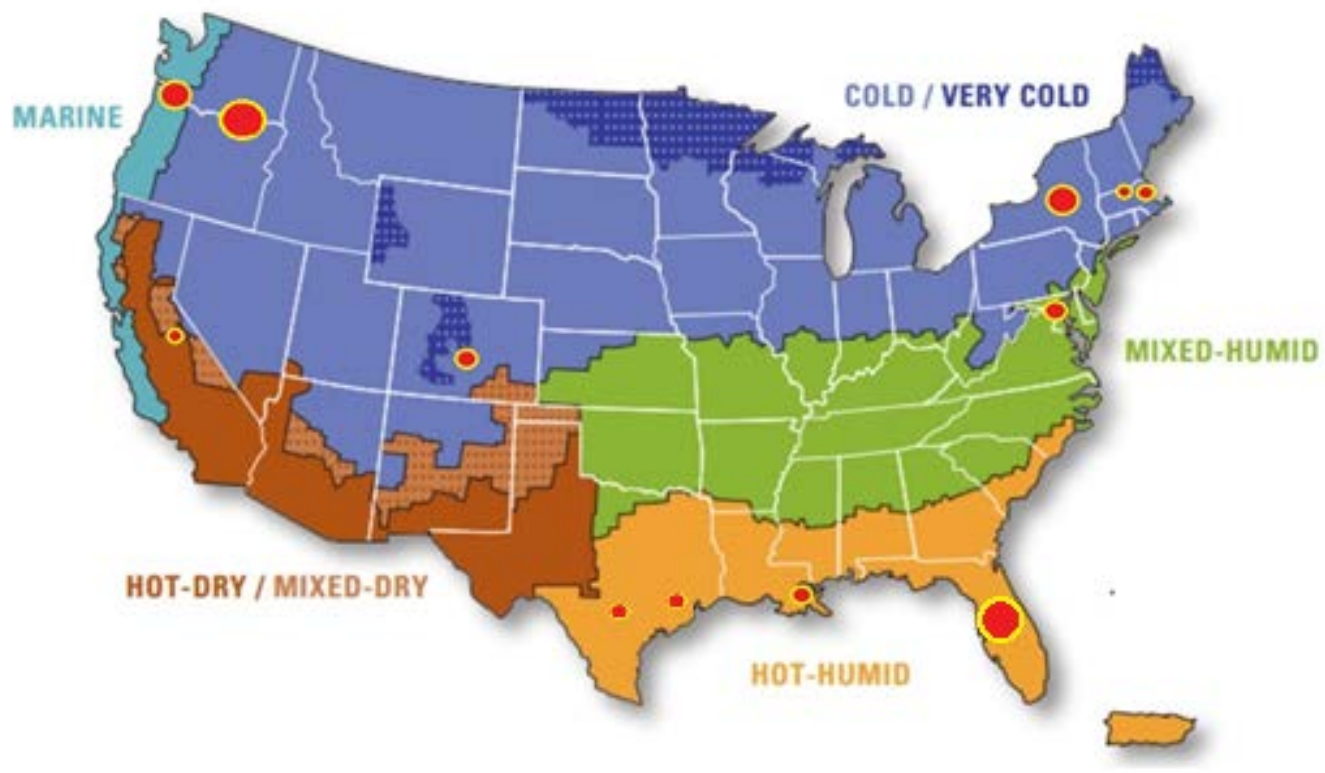

Figure 1. Locations of detailed data homes; marker size is approximately proportional to the number of monitored homes at that location 


\subsection{Web-Connected Thermostat Data}

Trane web-connected thermostats from thousands of locations across the country were used as a source of large-scale set point data. These systems provide very detailed data about the HVAC systems and indoor temperatures, but lack house characteristics and provide only approximate location information. Table 2 broadly categorizes this data according to climate.

Table 2. Locations of Web-Connected Thermostat Homes

\begin{tabular}{lll}
\hline Climate & Heating & Cooling \\
\hline Hot-Humid & 2714 & 4312 \\
Hot-Dry & 445 & 554 \\
Mixed-Humid & 3529 & 4146 \\
\hline Mixed-Dry & 29 & 35 \\
Marine & 593 & 468 \\
\hline Cold & 3163 & 2592 \\
Very Cold & 38 & 14 \\
\hline Total & $\mathbf{1 0 , 5 1 1}$ & $\mathbf{1 2 , 1 2 1}$ \\
\hline
\end{tabular}

Only datasets including location information were included in this analysis. Some systems provided data during cooling season only, others heating and cooling. In cold and very cold climates, some locations did not have enough cooling data to be included. Note that for webconnected thermostats, each house provides one sample per year. Therefore, houses that have multiple years of data contribute more than one data point to the set. 


\section{Results}

\subsection{Temperature Dependence on Housing Characteristics}

The detailed home data include home characteristics that could intuitively affect temperature and humidity. Multiple linear regressions are used to examine whether these known physical characteristics of the homes were correlated with heating/cooling set points. Results are listed in Table 3. It is not surprising that climate and equipment type are correlated with home temperature, and there was no statistically significant correlation of the detailed data temperatures to the other variables.

Table 3. Housing Characteristics' Correlation to Measured Temperatures

\begin{tabular}{|l|c|c|}
\hline Independent Variable & $\begin{array}{c}\text { Significant for } \\
\text { Heating Temp }\end{array}$ & $\begin{array}{c}\text { Significant for } \\
\text { Cooling Temp }\end{array}$ \\
\hline BA Climate Zone & $\mathrm{X}$ & $\mathrm{X}$ \\
\hline Housing Type & & \\
\hline Equipment Type: Heating & $\mathrm{X}$ & \\
\hline Equipment Type: Cooling & & $\mathrm{X}$ \\
\hline Foundation Type & & \\
\hline Conditioned Area & & \\
\hline Year of Construction & & \\
\hline Number of Bedrooms & & \\
\hline Number of Bathrooms & & \\
\hline Number of Floors & & \\
\hline
\end{tabular}

Results from indoor temperature analysis are shown in the next sections, broken out using these characteristics to enable building energy analysts to select the most appropriate set point assumptions for their use case.

\subsection{Mean Home Temperatures}

Because the total number of detailed homes is limited and the homes were tightly clustered, these data proved insufficient for performing nationwide, statistically significant home temperature set point estimations. These limitations are overcome in this study by evaluating web-connected thermostat data, in partnership with Trane. Web-connected thermostats provide reliable information on system operation across orders of magnitude more homes with more complete coverage of the United States. Therefore, all data were leveraged throughout the remainder of this document for determining representative temperature set points.

\subsubsection{Determination of Heating and Cooling Periods}

Throughout the year, there are days, or even months, when a given home is not actively heated or cooled by HVAC equipment. During these times, indoor temperatures float. It was important to exclude those temperatures from any analysis as they do not drive operation of the equipment. Further, it was important to classify the other measured indoor temperatures by whether they 
influence heating equipment or cooling equipment. This allowed independent analysis of heating and cooling set points.

In cases where the detailed home datasets did not include heating or cooling equipment runtime, it was necessary to estimate periods of active heating and cooling. For this study, it is assumed that cooling occurred when outdoor temperature rose above $80^{\circ} \mathrm{F}$ and heating occurred when it fell below $40^{\circ} \mathrm{F}$. For every hour when one of these conditions was met, the home was considered to be intentionally cooled or heated, and the measured indoor temperature was then averaged into the appropriate mean. Homes with less than 200 hours of heating or cooling data were omitted from aggregate analysis for each HVAC operating mode.

In contrast, data from web-connected thermostats include active operation of the equipment along with both actual measured temperature and set point temperature; only measured temperatures are used in this study. These data were easily filtered for operational mode (i.e., heating or cooling) and status (active or inactive). For the web-connected thermostat data, indoor temperatures are reported along with the current mode of operation (i.e., heating or cooling) and the capacity needed (i.e., the runtime calculated percent capacity needed to satisfy the demand of the zone). Periods of active heating are those times when the mode of operation indicates heating and the heating capacity requirement is non-zero (i.e., call for heat). Similarly, periods of active cooling are those times when the mode of operation indicated cooling and the capacity needed was greater than zero (i.e. call for cooling).

\subsubsection{Heating and Cooling Temperature Averages}

The mean temperature results for the homes in the detailed home dataset and the web-connected thermostat dataset are shown in Table 4. For the web-connected thermostats, the indoor temperatures are lower than HSP 2014 for heating and cooling assumptions by $1.0 \pm 0.1^{\circ} \mathrm{F}$ and $1.1 \pm 0.1^{\circ} \mathrm{F}$, respectively. The differences from HSPs in the detailed home datasets are even larger, specifically during the heating season. This suggests that the heating and cooling set points currently used with the HSPs may not provide an accurate representation of real-world conditions.

Table 4. Mean Heating and Cooling Values

\begin{tabular}{|c|c|c|c|c|c|c|}
\hline & \multicolumn{3}{|c|}{ Heating } & \multicolumn{3}{|c|}{ Cooling } \\
\hline & $\begin{array}{l}\text { Mean } \\
{\left[{ }^{\circ} \mathrm{F}\right]}\end{array}$ & $\begin{array}{l}\text { Number } \\
\text { of Homes }\end{array}$ & $\begin{array}{l}95 \% \text { confidence } \\
\text { Interval of Mean }\left[{ }^{\circ} \mathrm{F}\right]\end{array}$ & $\begin{array}{c}\text { Mean } \\
{\left[{ }^{\circ} \mathrm{F}\right]}\end{array}$ & $\begin{array}{l}\text { Number } \\
\text { of Homes }\end{array}$ & $\begin{array}{l}95 \% \text { confidence } \\
\text { Interval of Mean }\left[{ }^{\circ} \mathrm{F}\right]\end{array}$ \\
\hline Detailed Home Data & 67.2 & 203 & 0.6 & 74.6 & 177 & 0.8 \\
\hline $\begin{array}{l}\text { Web-Connected } \\
\text { Thermostat Data }\end{array}$ & 70.0 & 37,991 & 0.1 & 74.9 & 40,913 & 0.1 \\
\hline HSP & 71 & & & 76 & & \\
\hline $\begin{array}{l}\text { HSP Minus Detailed Home } \\
\text { Data }\end{array}$ & 3.8 & & & 1.4 & & \\
\hline $\begin{array}{l}\text { HSP Minus Web-Connected } \\
\text { Thermostat Data }\end{array}$ & 1.0 & & & 1.1 & & \\
\hline
\end{tabular}


Figure 2 and Figure 3 show heating and cooling temperature distribution findings. The wide distribution among heating and cooling temperature results suggest that single heating and cooling numbers may not be sufficient for an accurate representation of indoor temperature set points in building simulation. Additionally, the temperature distribution during the heating season in Figure 2 shows an unusual pattern between $67^{\circ} \mathrm{F}$ and $72^{\circ} \mathrm{F}$. This is likely an artifact of the relatively small sample size involved and that the data are not randomly sampled throughout the population; rather, are collected through several groups of homes, each of which can have similarities to each other. The much larger sample sizes of the web-connected thermostat data help alleviate this problem. Note that there are many variables, such as demographics and occupant income, which cannot be controlled for when comparing the detailed data and webconnected thermostat data. It is possible that unknown - yet statistically significant — differences between the homes or their owners could bias results.

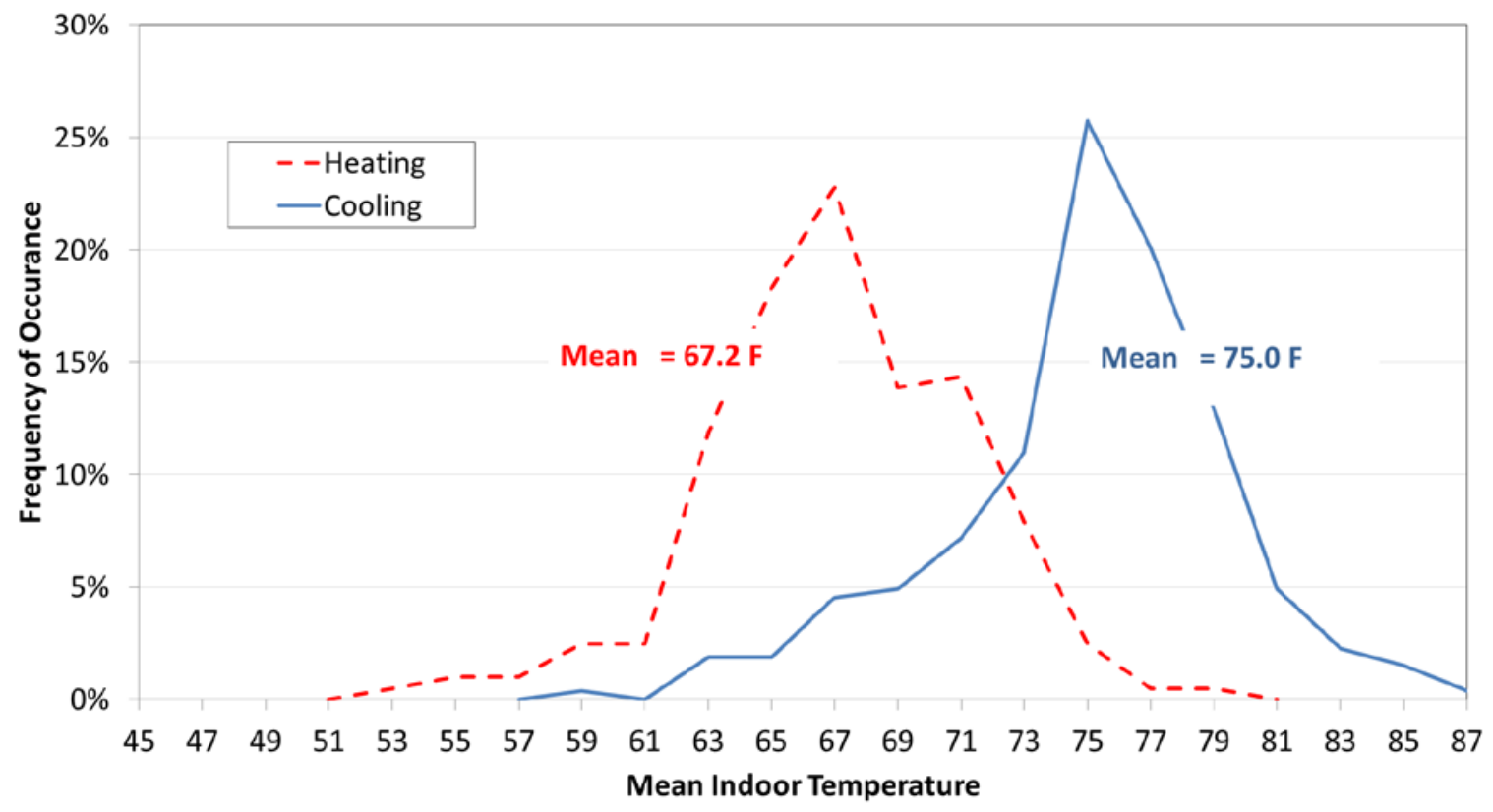

Figure 2. Mean annual indoor temperatures from detailed home data 


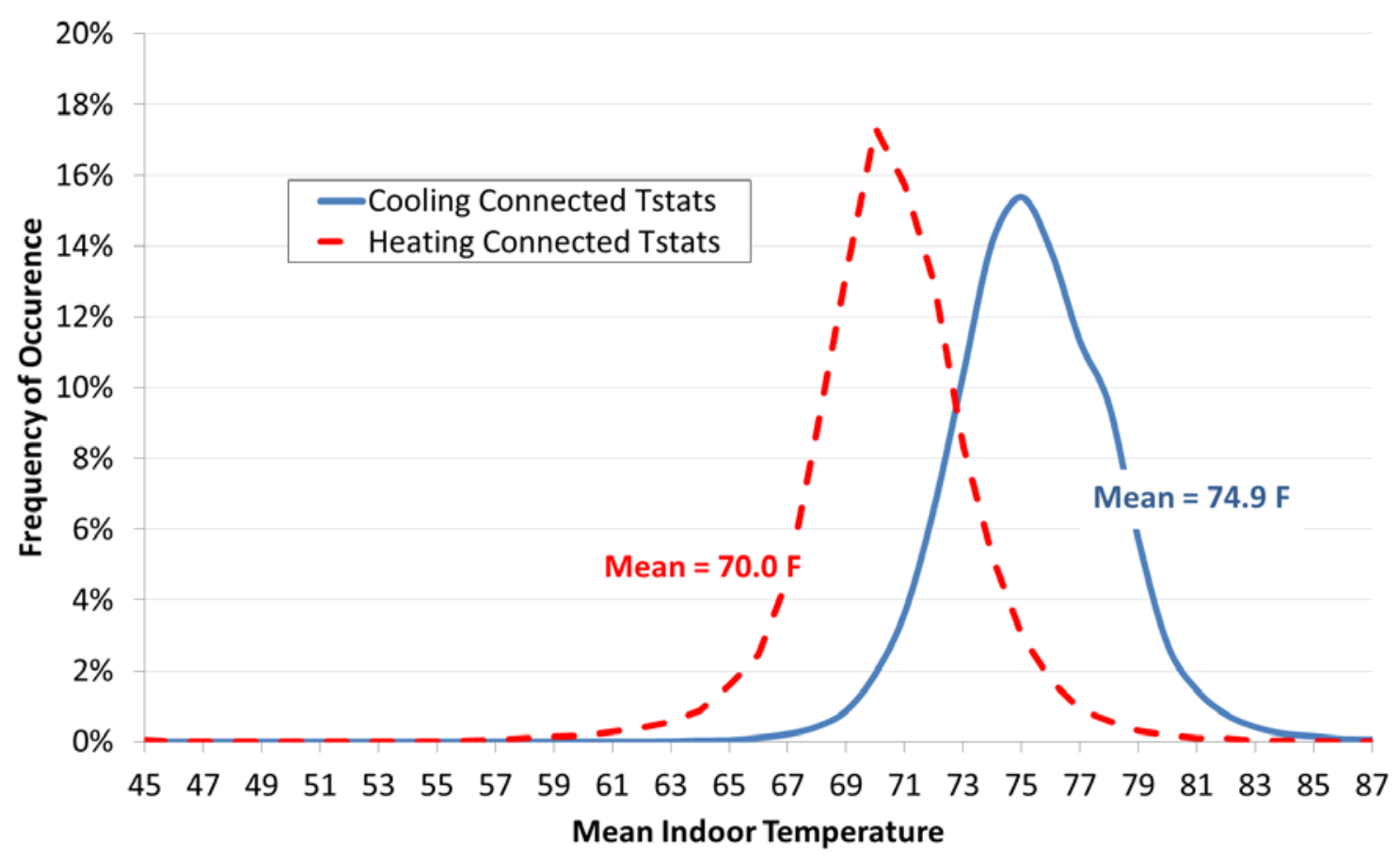

Figure 3. Mean annual indoor temperatures from web-connected thermostats

\subsubsection{Heating Results by Climate and Equipment Type}

Heating regression analysis showed a statistically significant effect of climate zone and space heating equipment on temperature; analysis results are provided in Table 5 through Table 7. Only web-connected thermostat data are included due to the relatively small sample size of detailed home data.

Table 5. Mean Annual Heating Temperatures by Climate

\begin{tabular}{lccc}
\hline & \multicolumn{3}{c}{ Connected Thermostats } \\
BA Climate Zone & Mean $\left[^{\circ} \mathrm{F}\right]$ & Count & $\begin{array}{c}\text { 95\% confidence } \\
\text { interval of Mean }\left[{ }^{\circ} \mathrm{F}\right]\end{array}$ \\
\hline Cold & 69.4 & 3686 & 0.1 \\
Hot-Dry & 70.7 & 544 & 0.2 \\
Hot-Humid & 70.5 & 3590 & 0.1 \\
Marine & 68.9 & 748 & 0.2 \\
Mixed-Dry & 69.8 & 47 & 0.9 \\
Mixed-Humid & 69.8 & 4281 & 0.1 \\
Very Cold & 66.3 & 42 & 1.2 \\
\hline
\end{tabular}


Table 6. Mean Annual Heating Temperatures by Equipment Type

\begin{tabular}{lccc}
\hline $\begin{array}{c}\text { Heating Equipment } \\
\text { Type }\end{array}$ & \multicolumn{3}{c}{ Connected Thermostats } \\
Mean $\left[{ }^{\circ} \mathrm{F}\right]$ & Count & $\begin{array}{c}95 \% \text { confidence } \\
\text { interval of Mean }\left[{ }^{\circ} \mathrm{F}\right]\end{array}$ \\
\hline AS Heat Pump & 69.9 & 18210 & $<0.05$ \\
Electric Furnace & 71.9 & 1046 & 0.2 \\
\hline Forced Air Furnace & 70.0 & 18118 & $<0.05$ \\
\hline
\end{tabular}

Table 7. Mean Annual Heating Temperatures by Equipment Type and Climate

\begin{tabular}{|c|c|c|c|c|}
\hline \multirow[b]{2}{*}{ BA Climate Zone } & \multirow[b]{2}{*}{$\begin{array}{l}\text { Heating Equipment } \\
\text { Type }\end{array}$} & \multicolumn{3}{|c|}{ Connected Thermostats } \\
\hline & & Mean $\left[{ }^{\circ} \mathrm{F}\right]$ & Count & $\begin{array}{c}\text { 95\% confidence } \\
\left.\text { interval of Mean [ }{ }^{\circ} \mathrm{F}\right]\end{array}$ \\
\hline \multirow{3}{*}{ Cold } & AS Heat Pump & 69.3 & 1260 & .02 \\
\hline & Electric Furnace & 71.9 & 1046 & 0.2 \\
\hline & Forced Air Furnace & 70.0 & 18118 & $<0.05$ \\
\hline \multirow{3}{*}{ Hot-Dry } & AS Heat Pump & 70.9 & 167 & 0.4 \\
\hline & Electric Furnace & 74.4 & 1 & - \\
\hline & Forced Air Furnace & 70.6 & 371 & 0.3 \\
\hline \multirow{3}{*}{ Hot-Humid } & AS Heat Pump & 70.4 & 1796 & 0.1 \\
\hline & Electric Furnace & 71.8 & 267 & 0.4 \\
\hline & Forced Air Furnace & 70.5 & 1475 & 0.2 \\
\hline \multirow{2}{*}{ Marine } & AS Heat Pump & 69.0 & 464 & 0.2 \\
\hline & Forced Air Furnace & 68.8 & 347 & 0.3 \\
\hline \multirow{2}{*}{ Mixed-Dry } & AS Heat Pump & 69.9 & 19 & 1.6 \\
\hline & Forced Air Furnace & 69.6 & 26 & 1.2 \\
\hline \multirow{3}{*}{ Mixed-Humid } & AS Heat Pump & 69.7 & 2766 & 0.1 \\
\hline & Electric Furnace & 67.8 & 4 & 1.7 \\
\hline & Forced Air Furnace & 70.0 & 1475 & 0.1 \\
\hline \multirow{2}{*}{ Very Cold } & AS Heat Pump & 64.7 & 4 & 5.8 \\
\hline & Forced Air Furnace & 67.6 & 27 & 1.2 \\
\hline
\end{tabular}

\subsubsection{Cooling Results by Climate and Equipment Type}

The following tables show the mean temperatures sorted by cooling equipment type and climate zone location of the homes. Tables $8-10$ show mean temperature results by equipment type and climate. All of the data point to climate as being an important characteristic for mean temperatures. Only web-connected thermostat data are included due to the relatively small sample size of detailed home data. 
Table 8. Mean Annual Cooling Temperatures by Climate

\section{Connected Thermostats}

\begin{tabular}{lccc} 
BA Climate Zone & Mean $\left[{ }^{\circ} \mathrm{F}\right]$ & Count & $\begin{array}{c}95 \% \text { confidence } \\
\text { interval of Mean }\left[{ }^{\circ} \mathrm{F}\right]\end{array}$ \\
\hline Cold & 74.3 & 2885 & 0.7 \\
Hot-Dry & 76.4 & 614 & 0.8 \\
Hot-Humid & 75.3 & 5058 & 0.7 \\
\hline Marine & 74.0 & 565 & 0.8 \\
Mixed-Dry & 76.0 & 46 & 1.1 \\
\hline Mixed-Humid & 74.4 & 4668 & 0.7 \\
Very Cold & 73.4 & 17 & 1.6 \\
\hline
\end{tabular}

Table 9. Mean Annual Cooling Temperatures by Cooling Equipment Type

\begin{tabular}{lccc}
\hline $\begin{array}{c}\text { Cooling Equipment } \\
\text { Type }\end{array}$ & \multicolumn{3}{c}{ Connected Thermostats } \\
& Mean $\left[{ }^{\circ} \mathrm{F}\right]$ & Count & $\begin{array}{c}95 \% \text { confidence } \\
\text { interval of Mean }\left[{ }^{\circ} \mathrm{F}\right]\end{array}$ \\
\hline AS Heat Pump & 74.8 & 19622 & $<0.05$ \\
Central AC & 75.0 & 19197 & $<0.05$ \\
\hline
\end{tabular}


Table 10. Mean Annual Cooling Temperatures by Equipment Type and Climate

\begin{tabular}{|c|c|c|c|c|}
\hline \multirow[b]{2}{*}{ BA Climate Zone } & \multirow[b]{2}{*}{$\begin{array}{c}\text { Cooling Equipment } \\
\text { Type }\end{array}$} & \multicolumn{3}{|c|}{ Connected Thermostats } \\
\hline & & Mean $\left[{ }^{\circ} \mathrm{F}\right]$ & Count & $\begin{array}{c}95 \% \text { confidence } \\
\text { interval of Mean }\left[{ }^{\circ} \mathrm{F}\right]\end{array}$ \\
\hline \multirow{2}{*}{ Cold } & AS Heat Pump & 74.1 & 1181 & 0.1 \\
\hline & Central AC & 74.3 & 1336 & 0.1 \\
\hline \multirow{2}{*}{ Hot-Dry } & AS Heat Pump & 76.8 & 179 & 0.5 \\
\hline & Central AC & 76.3 & 420 & 0.3 \\
\hline \multirow{2}{*}{ Hot-Humid } & AS Heat Pump & 75.4 & 2419 & 0.1 \\
\hline & Central AC & 75.3 & 2575 & 0.1 \\
\hline \multirow{2}{*}{ Marine } & AS Heat Pump & 73.7 & 376 & 0.3 \\
\hline & Central AC & 75.0 & 129 & 0.6 \\
\hline \multirow{2}{*}{ Mixed-Dry } & AS Heat Pump & 76.8 & 18 & 1.3 \\
\hline & Central AC & 75.9 & 23 & 1.2 \\
\hline \multirow{2}{*}{ Mixed-Humid } & AS Heat Pump & 74.5 & 3046 & 0.1 \\
\hline & Central AC & 74.4 & 1567 & 0.1 \\
\hline \multirow{2}{*}{ Very Cold } & AS Heat Pump & 74.5 & 3 & 5.0 \\
\hline & Central AC & 73.1 & 11 & 1.9 \\
\hline
\end{tabular}

\subsubsection{Heating and Cooling Trends}

Figure 4 shows the mean temperatures across climates for both heating and cooling seasons. The trends are similar across climates; higher cooling temperatures correspond to higher heating temperatures and vice versa.

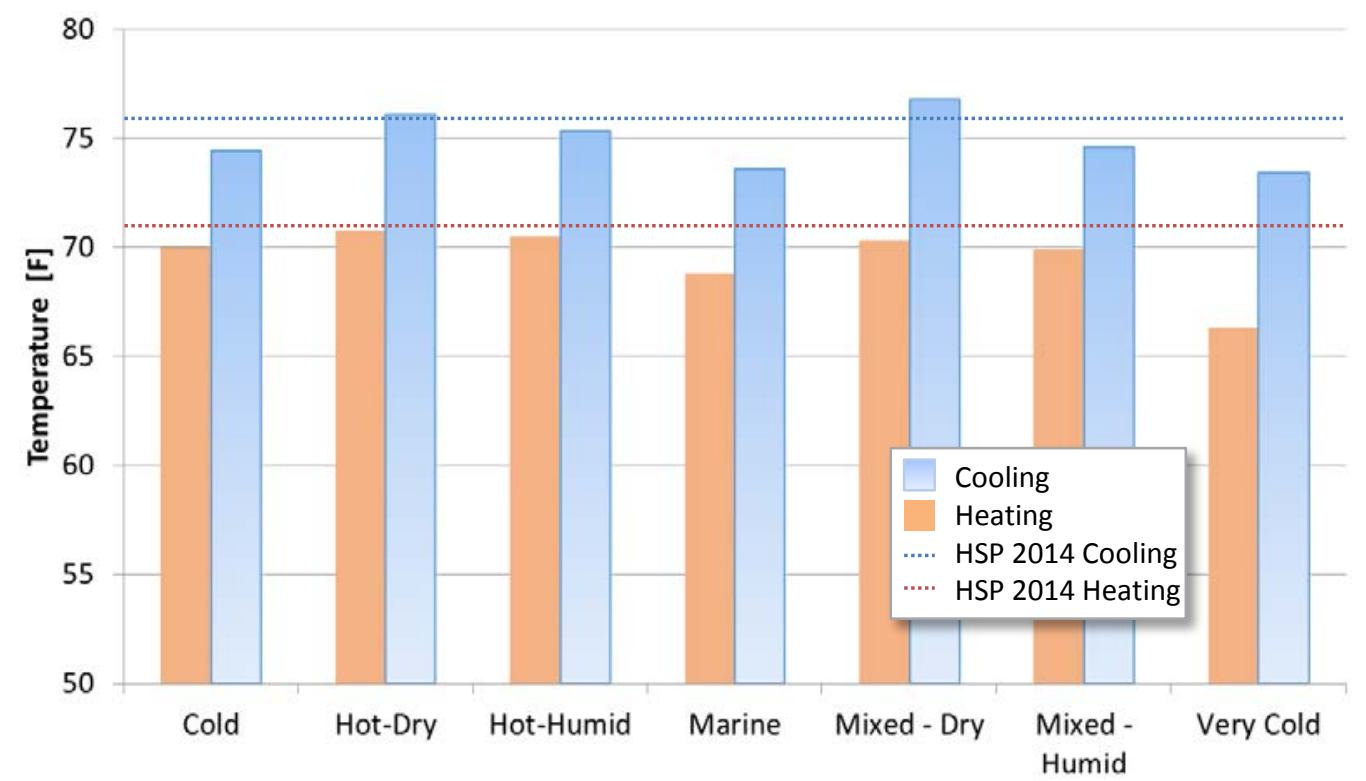

Figure 4. Mean annual indoor temperatures during heating and cooling for each climate 


\subsection{Impact on the House Simulation Protocols}

The findings of this study have the potential, if adopted by BA through the HSPs, to significantly change energy-use predictions. As an example of this impact, four 1980s vintage houses with construction features and HVAC equipment types matching the most common practice in the four different climate zones were simulated, with the only variation being temperature set point assumptions. Table 11 provides the results from these simulations.

Table 11. BEopt Energy Impact of Using Web-Connected Thermostat Temperature Findings Compared to HSP 2014 Assumptions

\begin{tabular}{|c|c|c|c|c|}
\hline \multirow{2}{*}{ Location } & \multicolumn{2}{|c|}{$\begin{array}{c}\text { Change in energy from lowering } \\
\text { heating set point by } 1.0^{\circ} \mathrm{F}\end{array}$} & \multicolumn{2}{|c|}{$\begin{array}{l}\text { Change in energy from lowering } \\
\text { cooling set point by } 1.1^{\circ} \mathrm{F}\end{array}$} \\
\hline & Heating & Whole Home & Cooling & Whole Home \\
\hline Seattle, WA & $-8 \%$ & $-3 \%$ & $8 \%$ & $0.2 \%$ \\
\hline Chicago, IL & $-5 \%$ & $-2 \%$ & $5 \%$ & $0.3 \%$ \\
\hline Atlanta, GA & $-8 \%$ & $-2 \%$ & $4 \%$ & $0.7 \%$ \\
\hline Houston, TX & $-11 \%$ & $-1 \%$ & $3 \%$ & $1 \%$ \\
\hline
\end{tabular}




\section{Conclusions}

The purpose of this study was to collect residential indoor temperature data and analyze it, adding to the body of knowledge regarding simulation assumptions for thermostat set points across the United States. Data were collected from across all U.S. climate regions in two ways: (a) by performing a detailed survey which measured indoor temperatures in one or more indoor locations including adjacent to thermostats, for 327 homes, and (b) by collecting data from webconnected thermostats in more than 12,000 homes. The authors believe this is the most complete U.S. housing set point survey performed to date.

Due to limited geographic coverage in the detailed data homes and limited housing characteristics in the web-connected thermostat data, both of these datasets were used to create a more comprehensive understanding of HVAC set point trends than either would make available on its own. Analysis of the detailed data clearly show that, among locational and physical home characteristics, only climate region and HVAC equipment type influence homeowner set points. Other potentially influential characteristics (i.e., insulation level, vintage, and size) were found independent from this control variable. Fortunately, the web-connected thermostat data include location and equipment type, and the large sample size enables higher statistical confidence in the results.

The measured mean indoor temperature observed from web-connected thermostats during the heating season was $70 \pm 0.1^{\circ} \mathrm{F}$. The mean indoor temperature observed during the cooling season was $74.9 \pm 0.1^{\circ} \mathrm{F}$. These are $1.0^{\circ} \mathrm{F}$ and $1.1^{\circ} \mathrm{F}$ lower, respectively, than HSP 2014 set point assumptions for heating and cooling. The mean temperatures can be further disaggregated based on climate and equipment type based on the results in Tables 5-10.

It is acknowledged that a sampling bias could result from the data collection sources that were available during the study. Occupants of BA "detailed data" research homes are typically more engaged in energy efficiency and the environment than the average American, and they were aware that their homes were being monitored. These factors could result in selection bias among the occupants and/or cause an observation bias since the homeowners knew the researchers were watching their energy performance. Further, if equipment or other systems are found to malfunction in BA homes, it is highly likely they will be repaired to facilitate the research goals of the project, leading to different thermal and energy outcomes than the general population of U.S. homes. As with other HVAC manufacturers, Trane web-connected thermostats are only available to homeowners who purchase higher-end Trane HVAC systems. Only more affluentthan-average homeowners are likely to purchase such systems, and those homeowners are expected to be less sensitive to utility costs, and thus may use HVAC set points that make them more comfortable than the overall population would select. Overall, these potential biases are understood; however, they could not be independently controlled for within the data means available. 


\section{Future Work}

In addition to temperature, humidity can play a substantial role in how HVAC systems operate in homes and how much energy they use. It is important to understand temporal fluctuations in humidity and how those can be categorized to better determine whether certain homes are likely to have air quality and/or durability problems. It is also important to understand what data are needed to quantify the air quality and durability risk of other homes and how this type of data can be used to help predict those problems so they can be remedied. A large humidity dataset of similar size and detail was collected in parallel with the temperature data from Trane, which can help answer some of these questions.

As noted previously, we hope to perform additional data collection and analysis to explore the potential data biases, revising our recommendations accordingly. Further, a longitudinal study could show how set point decisions are influenced by other factors such as climate change, higher-efficiency HVAC equipment, changing utility rates, or code-driven improvements in home construction. Increasing availability of data from "Internet of Things" devices promises to greatly accelerate our understanding of how homes are operated. 


\section{References}

ASHRAE Standard 55. (2013). "Thermal environmental conditions for human occupancy." Atlanta. Am. Soc. Heat. Refrig. Air-Cond. Eng. Inc.

Bagge, H.; Johansson, D. (2013). Indoor Moisture Conditions in Multifamily Dwellings: Measurements and Analysis. Building Physics, Lund University Lund, Sweden.

BEopt (2014). BEopt Version 2.2.0.1 https://beopt.nrel.gov.

DOE (2013). EnergyPlus (version 8.0.0.008). http://www.energyplus.gov.

Engebrecht-Metzger, C.; Norton, P. (2014). Building America Indoor Temperature and Humidity Measurement Protocol. NREL/TP-5500-61040. Golden, CO: National Renewable Energy Laboratory.

Fanger, P.O. (2001). "Human requirements in future air-conditioned environments." Int. J. Refrig. 24, pp. 148-153.

Fanger, P.O. (1970). "Thermal comfort" and "Prediction of human heat tolerance." In Goldman R.F. 1970. Environmental Stress: Individual Human Adaptations. New York, NY: Academic Press.

"Interpreting Regression Output." (2007). Princeton University. Accessed January 13, 2014 : http://dss.princeton.edu/online_help/analysis/interpreting_regression.htm

Johansson, D.; Bagge, H.; Lindstrii, L. (2013). Indoor Temperature - Analysis of Two Years of Measurements in 1300 Apartments in Sweden. Building Physics, Lund University Lund, Sweden.

Parker, D.S. (2013).Determining Appropriate Heating and Cooling Thermostat Set Points for Building Energy Simulations for Residential Buildings in North America. Florida Solar Energy Center, Cocoa, FL.

Poerschke, A.; Beach, R. (2015). Comfort in High-Performance Homes in a Hot-Humid Climate DOE/GO-102015-4762.

R Core Team. (2015). R: A language and environment for statistical computing. R Foundation for Statistical Computing, Vienna, Austria. http://www.R-project.org/

Roberts, D.; Lay, K. (2013). Variability in Measured Space Temperatures in 60 Homes, National Renewable Energy Laboratory. NREL/TP-5500-58059. Golden, CO: National Renewable Energy Laboratory.

Robertson, J.; Polly, B.; Collis, J. (2013) Evaluation of Automated Model Calibration Techniques for Residential Building Energy Simulation. NREL/TP-5500-60127. Golden, CO: National Renewable Energy Laboratory. 
Seryak, J.; Kissock, K. (2003). Occupancy and behavioral affects on residential energy use. American Solar Energy Society, Solar conference, Austin, Texas.

Storm, P.; Hannas, B.; Baylon, D.; Davis, B. (January 2013). Residential Building Stock Assessment: Manufactured Home Characteristics and Energy Use, Northwest Energy Efficiency Alliance. http://neea.org/docs/default-source/reports/residential-building-stock-assessment-manufactured-homes-characteristics-and-energy-use.pdf

U.S. Department of Energy, (September 2013). DOE Challenge Home Case Study, Transformations, Inc., Production House, Devens, MA, http://transformationsinc.com/press/PDF/DOE_Challenge_Home-2013 _Winner_Production_House.pdf

U.S. Department of Energy, Energy Efficiency and Renewable Energy. (December 2013). Case Study: Low Cost Evaluation of Energy Savings at the Community Scale, Fresno, CA. http://www.nrel.gov/docs/fy15osti/62120.pdf

Werling, E. (2013). Building America Roadmap to High Performance Homes. Presented at the Building America Technical Update Meeting - April 29, 2013. Denver, CO.

Wiehagen, J.; Del Bianco, M.; Wood, A. (February 2013). Greenbelt Homes Pilot Energy Efficiency Program Phase 1 Summary: Existing Conditions and Baseline Energy Use. http://www.nrel.gov/docs/fy13osti/56027.pdf

Wilson, E.; Engebrecht-Metzger, C.; Horowitz, S.; Hendron, R.. (2014). “2014 Building America House Simulation Protocols". NREL/TP-5500-60988. Golden, CO: National Renewable Energy Laboratory. 